\title{
CONCEITOS DE INTERDISCIPLINARIDADE SEGUNDO PROFESSORAS(ES) DE CIÊNCIAS EM SANTARÉM - PARÁ
}

\author{
Nathália Prado Oliveira Parente47 \\ Jaílson Santos de Novais 48
}

\section{RESUMO}

Esse trabalho objetivou acessar os conceitos que professoras(es) de Ciências têm a respeito do termo interdisciplinaridade e palavras correlatas (multi, pluri e transdisciplinaridade). Os sujeitos da pesquisa foram professoras(es) de Ciências que atuam na rede municipal de ensino em Santarém, Pará. Os dados obtidos por meio de questionários foram analisados segundo a técnica do Discurso do Sujeito Coletivo (DSC). Constatou-se que as(Os) professoras(es) já ouviram falar sobre o conceito de interdisciplinaridade, bem como o diferenciam de forma superficial de termos correlatos. As ideias centrais encontradas orientando os DSC foram: "Interdisciplinaridade é a interação entre as disciplinas ou áreas do conhecimento"; "Interdisciplinaridade como uma proposta de trabalho da escola, a fim de reunir as disciplinas"; "Multidisciplinaridade reúne várias disciplinas, sem relação direta, trabalhando o mesmo tema"; "Interdisciplinaridade envolve algumas disciplinas e multidisciplinaridade envolve todas as disciplinas"; "Pluridisciplinaridade é o agrupamento das disciplinas de forma ampla"; "Pluridisciplinaridade envolve relação entre diferentes disciplinas"; e "Na transdisciplinaridade, observamos o grau máximo de interação disciplinar". Conclui-se que iniciativas de formação continuada poderão ampliar a visão dos sujeitos entrevistados sobre o que é interdisciplinaridade, bem como sobre como cada um(a) pode, a partir da reflexão sobre suas práticas docentes, pô-la em ação.

Palavras-chave: Discurso do Sujeito Coletivo. Ensino de Ciências. Multidisciplinaridade.

\footnotetext{
47 Especialista em Ensino Interdisciplinar das Ciências e Meio Ambiente pelo Centro de Formação Interdisciplinar da UFOPA. Mestranda em Recursos Aquáticos Continentais Amazônicos pela UFOPA. E-mail: nathyepv_2010@hotmail.com.

48 Doutor em Botânica pelo Instituto Nacional de Pesquisas da Amazônia. Especialista em Educação a Distância pela Faculdade de Tecnologia e Ciências de Salvador. Coordenador da Licenciatura Interdisciplinar em Ciências da Natureza e suas Tecnologias da Universidade Federal do Sul da Bahia (UFSB), campus Sosígenes Costa. Docente dos Programas de PósGraduação em Sociedade, Ambiente e Qualidade de Vida (UFOPA), Recursos Naturais da Amazônia (UFOPA) e Ciências e Tecnologias Ambientais (UFSB). E-mail: jailson.novais@ufsb.edu.br.
} 


\title{
CONCEPTS OF INTERDISCIPLINARITY ACCORDING TO SCIENCE TEACHERS IN SANTARÉM - IN THE STATE OF PARÁ, BRAZIL
}

\begin{abstract}
This paper aimed to access science teachers' concepts concerning interdisciplinarity and related words (multi, pluri and transdisciplinarity). Science teachers from the municipal system of education in Santarém, in the state of Pará were interviewed. Data was collected through questionnaires and analyzed according to the Discourse of the Collective Subject technique (DCS). We verified that the teachers have already heard about the concept of interdisciplinarity and they differentiate it from similar terms superficially. The central ideas found were: "Interdisciplinarity is the interaction between school subjects or knowledge areas"; "Interdisciplinarity as a work proposal at school in order to bring together the subjects"; "Multidisciplinarity brings together several school subjects, without a clear relationship among them, but working with the same theme"; "Interdisciplinarity involves some school subjects, multidisciplinarity involves all subjects"; "Pluridisciplinarity involves the school subjects broadly"; "Pluridisciplinarity means the relationship among different school subjects" and "In the transdisciplinarity we observe the highest degree of interaction among school subjects". We conclude that initiatives focused on teacher continuing professional development might broaden the interviewees' view on what interdisciplinarity means, as well as on how each one can, based on the reflection on their teaching practices, put the concept of interdisciplinarity into practice.
\end{abstract}

Keywords: Discourse of the Collective Subject. Science Teaching. Multidisciplinarity.

\section{CONCEPTOS DE INTERDISCIPLINARIEDAD SEGÚN PROFESORAS/ES DE CIENCIAS EN SANTARÉM - PARÁ}

\section{RESUMEN}

El objetivo de este trabajo fue dar cuenta de los conceptos que profesores de Ciencias tienen respecto a la interdisciplinariedad $y / 0$ palabras correlacionadas (multi, pluri y transdisciplinariedad). Los sujetos de la investigación profesores de ciências que desempeññan fucniones en la red munipal de enseñanza de Santarém, Estado de Pará. Los datos se obtuvieron mediante cuestionarios y se analizarón mediante la técnica del Discurso del Sujeto Colectivo (DSC). Se constato que los profesores han oído hablar del concepto de interdisciplinariedad y lo diferencian de términos similares de manera superficial. Las ideas centrales obtenidas a partir de los resultados fueron: "La interdisciplinaridad es la interacción entre asígnaturas o áreas de conocimiento"; "Interdisciplinariedad como propuesta de trabajo en la escuela para reunir a las asígnaturas"; "La multidisciplinariedad une a varias asígnaturas, sin una relación clara entre ellos, sino trabajando con el mismo tema"; "La interdisciplinariedad involucra a algunas asígnaturas escolares, pero la multidisciplinariedad involucra a todas ellas"; "La pluridisciplinariedad involucra a las asígnaturas en una visión más amplia"; "Pluridisciplinariedad significa la relación entre diferentes asígnaturas"; y "En la transdisciplinariedad observamos el mayor 
grado de interacción disciplinaria". Concluimos que las iniciativas centradas en la formación continuada de los docentes pueden ampliar la visión de los entrevistados sobre lo que es la interdisciplinariedad, así como sobre cómo cada uno puede, a partir de la reflexión sobre sus prácticas docentes, poner el concepto en acción.

Palabras claves: Discurso del Sujeto Colectivo. Enseñanza de las Ciencias. Multidisciplinariedad.

\section{INTRODUÇÃO}

A interdisciplinaridade constitui-se tema de debate contínuo no meio educacional, sendo citada em diversos documentos oficiais que norteiam a educação no Brasil (MOZENA; OSTERMANN, 2014), inclusive na atual proposta da Base Nacional Comum Curricular, em discussão no Ministério da Educação (BRASIL, 2016). Além disso, a interdisciplinaridade revela-se como uma forma de pensar como superar a abordagem disciplinar fragmentária, vigente na maioria dos espaços educativos, a qual emprega poucas metodologias voltadas a um ensino contextualizado (AUGUSTO et al, 2004).

Apesar de ser uma discussão já iniciada há décadas no Brasil, no cotidiano escolar observa-se continuamente a perpetuação de metodologias, estratégias e procedimentos de ensino e gestão disciplinares, os quais dificultam a conquista de avanços mais significativos na direção de um ambiente educacional efetivamente aberto à interdisciplinaridade.

O desafio em discutir e implementar práticas interdisciplinares na escola perpassa por diversos obstáculos. Um exemplo disso é o modelo disciplinar e desconectado no qual a maioria dos cursos universitários baseiam-se para formar professoras(es), além da fragmentação estrutural dos currículos escolares, a resistência de educadoras(es) em libertar-se dos limites da sua disciplina e a exigência social da formação de profissionais e saberes cada vez mais utilitários (THIESEN, 2008).

Aliado a esses fatores, têm-se as dificuldades e obstáculos epistemológicos que as(os) profissionais da educação apresentam para discutir o próprio conceito de interdisciplinaridade e a sua implementação (PIERSON; NEVES, 2001). Longe de querermos uma definição 
controvertidamente disciplinar para esse tema, cremos ser importante ao(à) educador(a) ter clareza de possíveis elementos-chave que o(a) ajudem a pensar a interdisciplinaridade e a sua prática.

Ainda são incipientes as pesquisas que tratam da interdisciplinaridade no ensino de Ciências no Brasil, especialmente no que diz respeito à formação inicial de professores (FEISTEL; MAESTRELLI, 2012; MOZENA; OSTERMANN, 2014). Em parte, isso reflete o fato de que cursos licenciatura, também em Ciências da Natureza, com enfoque interdisciplinar é algo ainda recente no país (MACKEDANZ; ROSA, 2016). Como exemplo, temos a Licenciatura Interdisciplinar em Ciências da Natureza e suas Tecnologias, na Universidade Federal do Sul da Bahia, a Licenciatura em Ciências da Natureza, da Universidade Federal do Pampa (Unipampa), e a Licenciatura em Educação no Campo com habilitação em Ciências da Natureza, da Universidade Federal dos Vales do Jequitinhonha e Mucuri (UFVJM).

No presente trabalho, nós buscamos investigar o conceito que professoras(es) de Ciências da rede municipal de ensino em Santarém (Pará, Brasil) atribuem ao termo interdisciplinaridade e a outros termos correlatos (multi, pluri e transdisciplinaridade). Esperamos que tal discussão suscite novas investigações com vistas a aprofundar o conhecimento acerca das práticas desenvolvidas por professoras(es) de Ciências, sob uma ótica interdisciplinar, haja vista crermos que, assim como afirmam Mackedanz e Rosa (2016, p. 141), "o ensino de ciências é o local ideal para um laboratório interdisciplinar".

\section{ANTECEDENTES}

No Brasil, a discussão acerca do tema interdisciplinaridade ocorre desde a década de 1970 (FAZENDA, 2002), embora na década de 1960 já houvesse relato das primeiras experiências que objetivavam explorar essa abordagem então inovadora (POMBO, 2005). Porém, apenas algumas décadas depois a interdisciplinaridade obteve maior espaço para difundir-se 
nas escolas brasileiras, sendo considerada nos Parâmetros Curriculares Nacionais (PCN):

A interdisciplinaridade supõe um eixo integrador, que pode ser o objeto de desconhecimento, um projeto de investigação, um plano de intervenção. Nesse sentido, ela deve partir da necessidade sentida pelas escolas, professores e alunos de explicar, compreender, intervir, mudar, prever, algo que desafia uma disciplina isolada e atrai a atenção de mais de um olhar, talvez vários (BRASIL, 2002, p. 88-89).

A interdisciplinaridade surge como uma forma de inovação, num período onde a cultura decorrente da formação, materialização e ampliação da ciência moderna é duramente criticada por seus opositores (MANGINI; MIOTO, 2009). Ainda segundo esses autores, a partir da década de 1960, é possível identificar o aparecimento do termo e seus correlatos em documentos e registros históricos.

Fazenda (1994) descreve que o surgimento da interdisciplinaridade deu-se na França e na Itália, em meados da década de 1960. Esse período foi marcado por muitas revoltas estudantis que clamavam por uma reforma no ensino, onde questões sociais, políticas e econômicas pudessem ser contempladas. A interdisciplinaridade teria sido uma resposta a esses clamores, pois os problemas da época não poderiam ser solucionados por uma única disciplina ou área do saber.

No Brasil, a interdisciplinaridade difundiu-se no final da década de 1960, onde exerceria grande influência na elaboração da Lei de Diretrizes e Bases da Educação Nacional (LDB, Lei nº 5.692, de 11/08/1971), consolidando-se com a então nova LDB (Lei n. 9.394/1996) e com os PCN (FAZENDA, 1994; BRASIL, 2002).

Em termos de implementação, a interdisciplinaridade estabelece-se nos planos curricular, didático e pedagógico (LENOIR, 2001). No geral, quando se fala nesse termo, faz-se referência a uma espécie de interação entre as disciplinas ou áreas do saber, embora essa interação possa ocorrer em níveis de ordens diferentes (CARLOS, 2007). Para distinguir tais níveis, foram criados os termos multidisciplinaridade, pluridisciplinaridade, interdisciplinaridade e transdisciplinaridade. Esses termos foram propostos 
originalmente pelo austríaco Eric Jantsch e, então, modificados e adaptados pelo brasileiro Hilton Japiassu (JAPIASSU, 1976).

A multidisciplinaridade revela-se como o primeiro nível de integração entre os conhecimentos das disciplinas. Japiassu (1976) afirma que a multidisciplinaridade é caracterizada por uma ação simultânea de um conjunto de disciplinas em volta de um tema comum. Porém, essa atuação é muito quebrada, pois não há exploração da relação entre os conhecimentos disciplinares e nem qualquer tipo de relação entre as disciplinas propriamente ditas.

Partindo desta premissa, ressalta-se que na multidisciplinaridade os conhecimentos são tidos como estanques e permanecem todos em um mesmo nível de hierarquia, sem haver nenhuma "ponte" entre tais domínios disciplinares (CARLOS, 2007). Isso sugere a inexistência de alguma organização ou coordenação entre esses conhecimentos.

Enquanto isso, na pluridisciplinaridade há a presença de algum tipo de interação entre os conhecimentos disciplinares, diferentemente do nível anterior (CARLOS, 2007). No entanto, eles ainda permanecem em um mesmo nível hierárquico, não havendo ainda qualquer tipo de coordenação proveniente de um nível hierarquicamente superior. Para certas(os) especialistas, não há diferença entre a multidisciplinaridade e a pluridisciplinaridade, porém, Carlos (2007) prefere considerá-los separadamente, argumentando que a existência ou não de cooperação e diálogo entre as disciplinas justifica diferenciar tais níveis de interação.

$\mathrm{Na}$ interdisciplinaridade existe a presença de uma axiomática comum a um grupo de disciplinas conexas, ou seja, as disciplinas relacionam-se e correlacionam-se. Portanto, na interdisciplinaridade, existe a cooperação e - diálogo entre as disciplinas das diferentes áreas do conhecimento, tratando-se de uma ação coordenada (JAPIASSU, 1976).

Por fim, Japiassu (1976) define transdisciplinaridade como um nível de integração disciplinar além da interdisciplinaridade. Define-se como uma espécie de coordenação de "todas as disciplinas e interdisciplinas de um 
sistema de ensino inovador, sobre a base de uma axiomática geral" (JAPIASSU, 1976, p. 74).

Thiesen (2008) ilustra as interdisciplinas citadas acima por meio de exemplos vivenciados em campos da ciência contemporânea:

Como o campo da bioquímica, o da biofísica, o da engenharia e o da genética; estas duas últimas áreas - a engenharia e a genética cuja mistura parecia impensável há 60 ou 70 anos. Algumas delas têm sido designadas como ciências de fronteira - novas disciplinas que nascem nas fronteiras entre duas disciplinas tradicionais -, outras como interdisciplinas - aquelas que nascem na confluência entre ciências puras e ciências aplicadas. É nessa nova situação epistemológica que as novas disciplinas ou ciências vêm sendo constituídas (THIESEN, 2008, p. 550, grifo do autor).

Essas conexões entre áreas do conhecimento têm impacto direto no trabalho desenvolvido nos espaços educativos. Não são poucas(os) as(os) professoras(es) da educação básica, principalmente de Ciências e Biologia, que passam por situações constrangedoras por terem que ensinar conteúdos de outras disciplinas acadêmicas em sala de aula, sendo que não foram adequadamente formadas(os) para tal. Algumas(ns), por exemplo, recusamse a assumir as turmas nas quais são tratados, por tradição, conhecimentos específicos de Física e Química (REZENDE; QUEIROZ, 2009).

A dificuldade das(os) professoras(es) quanto à pouca discussão dos conteúdos escolares de forma interdisciplinar, por meio de projetos, dá-se devido ao fato da formação dessas(es) docentes ter sido fragmentada, seguindo o conservador modelo que divide os assuntos em disciplinas e promove pouco ou nenhum diálogo entre tais conteúdos. Isso ocasiona insegurança nessas(es) profissionais para trabalhar com atividades sob a ótica interdisciplinar, já que não foram orientadas(os) com base nessa concepção durante seu processo formativo inicial e continuado (KLEIMAN; MORAES, 2007; CZERNIAK; JOHNSON, 2014).

Diante disso, cabe ainda refletir a respeito do compromisso que a universidade tem em formar professoras(es) com uma visão interdisciplinar do processo de ensino-aprendizagem. É fundamental que sejam capazes de 
utilizar metodologias diversas que estimulem as(os) estudantes a relacionar o que aprendem nas escolas com o que vivenciam no dia-a-dia, de forma orgânica e sistêmica.

Segundo Broggy, O'Reilly e Erduran (2017, p. 82):

A qualidade do ensino que os professores oferecem aos estudantes em uma sala de aula é altamente dependente do que os professores fazem na sala de aula. Num tempo em que há uma demanda por mão de obra especializada em carreiras STEM [com foco em Ciências, Tecnologia, Engenharia e Matemática, na sigla em inglês], que possa enfrentar de forma sábia os complexos problemas da vida real, devemos assegurar que o ensino de Ciências e das disciplinas STEM seja eficaz, proporcionando oportunidades para tal (livre tradução nossa, grifo dos autores) ${ }^{49}$.

Assim, percebemos o papel de destaque que o(a) professor(a) de Ciências tem frente aos desafios que se apresentam na sociedade atual, seja como formador(a) de sujeitos que atuarão propositivamente nessa sociedade, ou enquanto profissional que investiga a sua própria prática e identifica caminhos para potencializá-la a cada dia. Compreender a dinâmica do trabalho interdisciplinar pode ser um elemento catalisador nesse processo.

\section{PROCEDIMENTO METODOLÓGICO}

A pesquisa teve caráter qualitativo, uma vez que, segundo Flick (2009), nesse âmbito busca-se valorizar a perspectiva dos participantes e sua diversidade, a reflexividade do pesquisador e da pesquisa, a apropriabilidade de métodos e teorias e a variedade de abordagens e de métodos.

Os dados dessa pesquisa provieram da coleta e análise de material descritivo, a partir da livre resposta dos sujeitos participantes a questões abertas e fechadas, haja vista os questionários serem uma das técnicas mais

\footnotetext{
49 "The quality of education that teachers provide to the students in a classroom is highly dependent upon what teachers do in the classroom. At a time when there is a demand for a skilled workforce in STEM careers who can tackle complex real life problems wisely we must ensure the teaching of science and STEM subjects is effective by providing opportunities for this" (BROGGY; O'REILLY; ERDURAN, 2017, p. 82 - grifo dos autores).
} 
usadas para coleta de dados primários (GRAY, 2012). Com isso, teve-se o intuito de acessar o conceito dos sujeitos sobre o termo interdisciplinaridade, eventualmente diferenciá-lo de palavras correlatas, bem como colher informações para uma caracterização geral da atuação profissional das(os) informantes.

Segundo a Secretaria Municipal de Educação (SEMED) de Santarém (PA), na zona urbana do município existem 53 escolas, sendo que, deste total, 15 ofertam o Ensino Fundamental II (6 $6^{\circ}$. ao $9^{\circ}$. anos), com a atuação de 19 professoras(es) de Ciências.

A partir dessa informação, enviamos à direção de cada escola um ofício solicitando que nos autorizassem a executar a pesquisa com as(os) professoras(es) de Ciências lotadas(os) em cada estabelecimento de ensino. Após a autorização concedida pelas(os) diretoras(es) das escolas, as(os) professoras(es) de Ciências foram convidadas(os) a participarem da pesquisa. Das(os) 19 docentes atuando com o ensino de Ciências na zona urbana do município, 11 dispuseram-se a participar do projeto e assinaram o Termo de Consentimento Livre e Esclarecido.

Após essa etapa, aos sujeitos foi entregue um questionário composto por 17 perguntas. A primeira parte do questionário objetivou colher dados para a caracterização socioprofissional dos sujeitos entrevistados (gênero, idade, há quanto tempo atua como professor(a), em qual(is) nível(is) de ensino atua, qual o curso de graduação e/ou pós-graduação cursado(s), e ano de conclusão dos referidos cursos).

A segunda parte do questionário, por sua vez, deteve-se em questionar à(ao) entrevistada(o): "Em sua opinião, o que é interdisciplinaridade?". Além disso, foi perguntado se o sujeito considerava haver diferença entre esse termo e cada um dos demais correlatos (multi, pluri e transdisciplinaridade). Em caso afirmativo, era ainda questionado: "Qual é essa diferença?". A resposta a essas questões abertas foi a principal fonte de análise qualitativa de nosso interesse. 
Tendo em vista que um questionário reflete, de certa forma, a visão de mundo de quem o elaborou, conforme aponta Gray (2012), optou-se por ser o mais objetivo possível na formulação das perguntas, a fim de obter com a máxima confiabilidade possível as concepções dos(as) participantes.

Os dados referentes à caracterização dos sujeitos foram reunidos e categorizados em planilha eletrônica, e estão apresentados em tabelas.

Os dados qualitativos foram analisados por meio do Discurso do Sujeito Coletivo (DSC) (LEFÈVRE; LEFÈVRE, 2005a,b), o qual consiste em uma metodologia de preparo e processamento do "corpus" de depoimentos que revela o pensamento do coletivo, expressando o "porquê" de pensarem dessa maneira. O DSC consiste:

(...) numa forma não-matemática nem metalinguística de representar (e de produzir), de modo rigoroso, o pensamento de uma coletividade, o que se faz mediante uma série de operações sobre os depoimentos, que culmina em discursos-síntese que reúnem respostas de diferentes indivíduos, com conteúdos discursivos de sentido semelhante (LEFÈVRE; LEFÈVRE, 2005a, p. 25).

Esse discurso das coletividades é elaborado a partir da localização, nos discursos individuais, de expressões-chave (EC), que são trechos selecionados do material verbal de cada depoimento que melhor descrevem seu conteúdo (LEFÈVRE; LEFÈVRE, 2005a,b). Estas EC são então reunidas em ideias centrais (IC), definidas como fórmulas sintéticas que descrevem os sentidos presentes nos depoimentos de cada resposta e também no conjunto de respostas de diferentes indivíduos, apresentando sentido semelhante ou complementar. Um DSC é gerado para cada IC identificada.

\section{RESULTADOS E DISCUSSÃO}

No que diz respeito à caracterização das(os) professoras(es) participantes desta pesquisa quanto ao gênero, formação acadêmica e atuação profissional, constatou-se que a maioria é do gênero feminino (9 professoras/es), graduou-se em Ciências Biológicas (7), cursou universidade 
pública (7), não possui pós-graduação (7) e trabalha com Ensino Fundamental II (7) (Tabela 1).

Tabela 1 - Caracterização das(os) entrevistadas(os) quanto ao gênero, formação acadêmica e atuação profissional

\begin{tabular}{ll}
\hline Variáveis & Descritores (n) \\
\hline Gênero & Feminino (9) \\
\hline \multirow{2}{*}{$\begin{array}{l}\text { Curso de graduação cursado pela(o) } \\
\text { entrevistada(o) }\end{array}$} & Ciênculiaso (2) Biológicas (7) \\
& Ciências Naturais (2) \\
\hline Tipo de instituição de ensino frequentada na & Matemática (1) \\
graduação & Pedagogia (1) \\
\hline \multirow{2}{*}{ Ano de conclusão da graduação } & Pública (7) \\
& $1995-1999(3)$ \\
\hline Possui pós-graduação? & 2000 - 2004 (1) \\
\hline \multirow{2}{*}{ Com qual nível escolar você trabalha atualmente? } & 2005 - 2009 (7) \\
\hline
\end{tabular}

Fonte: Questionários de pesquisa de campo, 2012.

O tempo de atuação dos(as) entrevistados(as) como professor(a) variou entre 9 meses e 29 anos. Além disso, todas(os) as(os) entrevistadas(os) declararam já terem ouvido falar sobre o termo interdisciplinaridade. A maioria afirmou que há diferença entre os termos inter, multi, pluri e transdisciplinaridade (Tabela 2).

Tabela 2 - Entendimento das(os) professoras(es) entrevistadas(os) no que diz respeito à diferença entre interdisciplinaridade e termos correlatos

\begin{tabular}{lccc}
\hline Questões & Sim & Não \\
\hline Você já ouviu falar em Interdisciplinaridade? & 11 & - \\
\hline Em sua opinião, há diferença entre os termos abaixo? & & \\
\hline - interdisciplinaridade $\times$ multidisciplinaridade & 8 & 3 \\
\hline - interdisciplinaridade $\times$ pluridisciplinaridade & 6 & 5 \\
\hline - interdisciplinaridade $\times$ transdisciplinaridade & 6 & 5 \\
\hline
\end{tabular}

Fonte: Questionários de pesquisa de campo, 2012. 
No total, foram obtidas sete ideias centrais (IC) vinculadas às perguntas apresentadas no questionário sobre interdisciplinaridade e termos afins (Tabela 3).

Tabela 3 - Ideias centrais (IC) identificadas nos discursos dos sujeitos participantes da pesquisa, representando os discursos do sujeito coletivo

Questões

Em sua opinião, o que é interdisciplinaridade?
Ideias Centrais (IC)

IC 1: Interdisciplinaridade é a interação entre as disciplinas ou áreas do conhecimento

IC 2: Interdisciplinaridade como uma proposta de trabalho da escola, a fim de reunir as disciplinas

IC 1: Multidisciplinaridade reúne várias disciplinas, sem possuírem relação, trabalhando o mesmo tema

Para você, há diferença entre interdisciplinaridade e multidisciplinaridade?

IC 2: Interdisciplinaridade envolve algumas disciplinas e multidisciplinaridade envolve todas as disciplinas

IC 1: Pluridisciplinaridade é o agrupamento das disciplinas de forma ampla

Para você, há diferença entre interdisciplinaridade e pluridisciplinaridade?

IC 2: Pluridisciplinaridade envolve relação entre diferentes disciplinas

IC 1: Na transdisciplinaridade observamos o grau máximo de interação disciplinar

Para você, há diferença entre

interdisciplinaridade e

transdisciplinaridade?

Fonte: Questionários de pesquisa de campo, 2012.

\section{1 "Em sua opinião, o que é interdisciplinaridade?"}

No que diz respeito à pergunta "Em sua opinião, o que é interdisciplinaridade?", oito professoras(es) responderam de forma aproximada ao conceito adotado por Japiassu (1976). A IC gerada foi "Interdisciplinaridade é a interação entre as disciplinas ou áreas do conhecimento". O DSC obtido reuniu oito discursos individuais:

Eu penso que interdisciplinaridade é a interação entre as disciplinas ou áreas do conhecimento que trabalham em torno de uma atividade. Podendo-se entender também como o diálogo entre diferentes disciplinas, compreendendo proximidade, convergência, contato e interação. Busca a solução dos problemas através da articulação de disciplinas. A interdisciplinaridade pode ainda ser analisada como uma habilidade de se trabalhar um ou mais temas abordando várias áreas do conhecimento. Além se ser a junção de vários conhecimentos de diversas disciplinas, com o intuito de superar o conceito de disciplinaridade (QUESTIONÁRIOS DE CAMPO, 2012). 
É importante notar a menção aos termos "interação" e "articulação" entre as disciplinas, uma vez que eles são a base do conceito de interdisciplinaridade e a caracterizam. Isso também é afirmado por Ribeiro (2005) em sua abordagem sobre essa temática, quando menciona que, para haver interdisciplinaridade, é necessário interação entre várias áreas. Além do diálogo entre áreas, no geral, as discussões sobre a atividade interdisciplinar incluem o ato de debruçar-se sobre um tema ou problema gerador. Isso é pouco mencionado pelas(os) professoras(es), conforme também notado por Barbosa (2016), durante pesquisa com professores de Ciências de Planaltina, DF.

Por outro lado, cinco professoras(es) descreveram uma resposta que gerou a segunda IC para a questão apresentada acima: "Interdisciplinaridade como uma proposta de trabalho da escola, a fim de reunir as disciplinas". Obteve-se o seguinte DSC:

Eu penso que a interdisciplinaridade é a comunicação de qualquer disciplina e que as pessoas trabalham juntos os temas propostos. É também um trabalho que a escola pode desenvolver entre várias disciplinas com objetivo de se trabalhar determinados conteúdos ao longo do ano letivo de forma intencional, ou seja, com objetivo de levar o aluno a refletir sobre tais conteúdos (QUESTIONÁRIOS DE CAMPO, 2012).

A interdisciplinaridade não deve ser vista apenas como uma atividade escolar. Ela é a superação da disciplinaridade, permitindo que se observe a realidade em sua totalidade (RIBEIRO, 2005). Devido a esse "rompimento" das especificidades, a interdisciplinaridade apresenta-se como dificuldade, uma vez que $o$ indivíduo habituou-se a entender a realidade de forma fragmentada.

Carminatti e Del Pino $(2015$, p. 114) afirmam que:

Um dos grandes entraves para construção da interdisciplinaridade é a dificuldade na compreensão deste termo, ou seja, às vezes, os educadores têm uma concepção insuficiente a respeito dessa forma de trabalhar [a interdisciplinaridade] e, portanto, não conseguem refletir sobre suas ações neste sentido. 
A dificuldade que professoras(es) têm em conceituar interdisciplinaridade é algo também apontado por outros trabalhos (LAVAQUI; BATISTA, 2007; BARBOSA, 2016).

\section{2 "Para você, há diferença entre interdisciplinaridade e multidisciplinaridade?"}

Na pergunta "Para você, há diferença entre interdisciplinaridade e multidisciplinaridade?", oito professoras(es) responderam que havia diferença entre esses termos e três disseram não haver diferença entre eles.

Ao explicarem a diferença entre os termos, os discursos geraram a IC "Multidisciplinaridade reúne várias disciplinas, sem possuírem relação, trabalhando o mesmo tema". Cinco discursos individuais reunidos geraram o seguinte DSC:

Eu penso que há diferença entre os conceitos de Inter e Multidisciplinaridade, sendo a interdisciplinaridade uma forma de se abordar um mesmo assunto em várias áreas do conhecimento, de maneira integrada, por meio de diálogos e contrapontos entre as disciplinas. Já a multidisciplinaridade seria uma forma de se trabalhar várias disciplinas, sem a necessidade de trabalhá-las em conjunto, sem ocorrer relação entre elas, de forma fragmentada, ou seja, de maneira tradicional (QUESTIONÁRIOS DE CAMPO, 2012).

No discurso acima, observa-se que a diferença entre os conceitos de interdisciplinaridade e multidisciplinaridade está pautada no termo "relação". O DSC afirma não haver interação entre as disciplinas quando se tem multidisciplinaridade, contrariamente ao que ocorre na interdisciplinaridade. Esse ponto de vista assemelha-se à visão segundo a qual a interdisciplinaridade é promotora da interação entre disciplinas, enquanto que na multidisciplinaridade não há interação entre as áreas, ainda que um tema em comum seja abordado por todas as disciplinas (SCHMITT et al, 2006). Conforme Martins, Lechugo e Goergen (2013), a multidisciplinaridade aproxima as disciplinas, no entanto, os(as) especialistas responsáveis pelas mesmas continuam distantes entre si, sem interação e diálogo efetivo. Com isso, a atividade multidisciplinar preserva separadas as identidades de cada disciplina (BROGGY; O'REILLY; ERDURAN, 2017). 
Em contrapartida, três professoras(es) descreveram a diferença entre Inter e Multidisciplinaridade a partir da IC "Interdisciplinaridade envolve algumas disciplinas e multidisciplinaridade envolve todas as disciplinas":

\begin{abstract}
Eu penso que há diferença entre os termos Inter e multidisciplinaridade. A interdisciplinaridade busca trabalhar conteúdos em mais de uma disciplina de forma específica envolvendo algumas disciplinas. A multidisciplinaridade é notada no momento em que se abrange um determinado conteúdo, sem se preocupar em separar por disciplina, trabalhando-se de uma forma geral, envolvendo todas as disciplinas, trabalhando não só o conteúdo, mas a disciplina em questão (QUESTIONÁRIOS DE CAMPO, 2012).
\end{abstract}

Os conceitos interdisciplinaridade e multidisciplinaridade não são diferenciados pela quantidade de disciplinas que abordam um mesmo tema, como sugerido pelo DSC descrito acima, mas baseiam-se na já citada "interação" entre as áreas. A presença ou ausência dessa interação é o que caracteriza cada conceito.

\title{
4.3 "Para você, há diferença entre interdisciplinaridade pluridisciplinaridade?"
}

Quando questionados sobre a existência de diferença entre os termos inter e pluridisciplinaridade, 6 professoras(es) disseram que há diferença entre ambos, enquanto que 5 professoras(es) responderam não haver tal separação. Das respostas afirmativas, apenas uma mostrou relação com o conceito de Japiassu (1976), gerando a IC "Pluridisciplinaridade é o agrupamento das disciplinas de forma ampla", originando o seguinte discurso:

Eu penso que há diferença entre os termos inter e pluridisciplinaridade. $\mathrm{Na}$ interdisciplinaridade tem-se uma reciprocidade, de mutualidade, em regime e copropriedade, que possibilita um diálogo mais fecundo entre os vários campos do saber. $\mathrm{Na}$ pluridisciplinaridade, o agrupamento das disciplinas se faz de forma mais ampla entre aquelas que possuem algumas relações entre si, visando à construção de um sistema de um só nível, com objetivos distintos (QUESTIONÁRIOS DE CAMPO, 2012). 
Nesse discurso, a pluridisciplinaridade é diferenciada da interdisciplinaridade por estar em um mesmo nível hierárquico, sendo que, por outro lado, a segunda apresenta um nível hierárquico superior (CARLOS, 2007). Além disso, na interdisciplinaridade há maior interação entre as disciplinas.

Por outro lado, os discursos de 4 professoras(es) não seguiram a IC anterior, gerando uma nova IC: "Pluridisciplinaridade envolve relação entre diferentes disciplinas". O DSC originado é o seguinte:

\footnotetext{
Eu entendo que na iJnter temos a interação de duas ou mais disciplinas e na pluri ocorre relação entre diferentes disciplinas. Na pluridisciplinaridade as disciplinas são trabalhadas juntas, mas é possível observar algumas relações entre elas. Pluridisciplinaridade é uma relação entre as disciplinas de uma forma mais ampla, na qual as disciplinas se complementam (QUESTIONÁRIOS DE CAMPO, 2012).
}

Segundo Japiassu (1976), a diferença entre pluri e interdisciplinaridade não está relacionada ao fato de as disciplinas serem diferentes ou não, mas no nível de interação entre elas e no que diz respeito à hierarquia. E, para se ter pluridisciplinaridade, não necessariamente as disciplinas devem se complementar. Porém, esse conceito descrito no discurso aproxima-se daquele citado por Ribeiro (2005, p. 24), que descreve a pluridisciplinaridade como "um encontro em torno de um tema comum entre investigadores, professoras(es) de disciplinas distintas em que cada uma conserva a sua especificidade e seus métodos".

\section{4 "Para você, há diferença entre interdisciplinaridade e transdisciplinaridade?"}

No que diz respeito à diferença entre os conceitos de inter e transdisciplinaridade, seis professoras(es) responderam que havia diferença entre eles e cinco responderam negativamente. Um professor respondeu que havia diferença entre os termos inter e transdisciplinaridade, mas não soube explicar tal relação. 
A IC nesta questão foi a seguinte: "Na transdisciplinaridade observamos o grau máximo de interação disciplinar". O DSC gerado foi resultado de seis discursos individuais:

\begin{abstract}
Eu penso que há diferença entre os termos inter e transdisciplinaridade. A interdisciplinaridade trabalha com as disciplinas fazendo a relação existente entre os conteúdos, enquanto a transdisciplinaridade não significa apenas que as disciplinas trabalham entre si, mas que existe um pensamento organizador que ultrapassa as próprias disciplinas, representando um nível máximo de interação disciplinar. É uma proposta inovadora, indo muito além do conteúdo elaborado de forma sistemática pelo professor, envolvendo fatores relacionados à formação do indivíduo, cuja escola tem seu papel nessa formação (QUESTIONÁRIOS DE CAMPO, 2012).
\end{abstract}

Em relação à transdisciplinaridade, é um termo posterior aos demais, como o próprio DSC sugere, descrevendo-o como uma nova proposta. O termo foi conceituado também dessa forma no DSC, quando este cita a transdisciplinaridade como "um nível máximo de interação disciplina". Para Martins, Lechugo e Goergen (2013, p. 41), "a educação transdisciplinar oferece ao indivíduo uma formação que ultrapassa as barreiras das disciplinas e proporciona um movimento para além do disciplinar".

\title{
5 CONSIDERAÇÕES FINAIS
}

A maioria das(os) professoras(es) declarou compreender os conceitos de interdisciplinaridade e termos correlatos, bem como as diferenças existentes entre estes. Porém, a tarefa de conceituar os termos ou diferenciálos não mostrou ser uma tarefa fácil. Isso não nos causa estranhamento, uma vez que se admite que a interdisciplinaridade não possui um conceito estático e inflexível, especialmente quando se consideram diferentes concepções epistemológicas (LAVAQUI; BATISTA, 2007).

Também a maioria dos sujeitos entrevistados afirmou haver diferença entre os termos inter e multidisciplinaridade, bem como haver diferença entre os termos inter e pluridisciplinaridade, inter e transdisciplinaridade. 
Iniciativas de formação continuada focadas em práticas interdisciplinares são necessárias para ampliar a visão que as(os) professoras(es) de Ciências têm acerca da interdisciplinaridade, bem como para que possam refletir sobre as suas práticas docentes e ressignificá-las sob uma perspectiva mais integradora.

Por não haver pesquisas nessa vertente na região amazônica, esse trabalho poderá servir de subsídio para outras investigações e projetos de intervenção que auxiliem as(os) professoras(es) a trabalharem em uma perspectiva interdisciplinar, haja vista o destaque desse conceito no atual cenário educacional.

\section{AGRADECIMENTOS}

Às professoras e aos professores das escolas que gentilmente aceitaram participar desse trabalho. À Dra. Iani Laver Leite (CFI/UFOPA), pela valiosa contribuição durante a discussão metodológica. Ao Prof. Daniel Augusto Ramirez-Cotes (Universidad del Tolima, Colômbia), pelo auxílio com o Resumen.

\section{REFERÊNCIAS}

AUGUSTO, T. G. S.; CALDEIRA, A. M. A.; CALUZI, J. J.; NARDI, R. Interdisciplinaridade: concepções de professores da área ciências da natureza em formação em serviço. Ciência \& Educação, Bauru, v. 10, n. 2, p. 277-289, 2004.

BARBOSA, W. S. A interdisciplinaridade no ensino de ciências: uma investigação sobre a percepção dos professores. 21f. Monografia (Licenciatura em Ciências Naturais) - Universidade de Brasília, Brasília/DF, 2016.

BRASIL. Ministério da Educação. Secretaria de Educação Média e Tecnológica. Parâmetros Curriculares Nacionais: Ensino Médio. Brasília: Ministério da Educação, 2002.

BRASIL. Ministério da Educação. Base Nacional Comum Curricular. 2. ed. revista. em: <http://basenacionalcomum.mec.gov.br/documentos/bncc2versao.revista.pdf $>$. Acesso em: 18.jan.2017. 
BROGGY, J.; O'REILLY, J.; Interdisciplinaridade e transdisciplinaridade na formação de professoresERDURAN, S, Interdisciplinarity and science education. In: TABER, K. S.; AKPAN, B. (Eds.). Science education: an international course companion. Rotterdam: Sense Publishers, 2017. p. 81-90.

CARLOS, J. G. Interdisciplinaridade no Ensino Médio: desafios e potencialidades. 171f. Dissertação (Mestrado em Ensino de Ciências) Universidade de Brasília, Brasília/DF, 2007.

CARMINATTI, B.; DEL PINO, J. C. Concepções dos professores da área das ciências da natureza acerca da construção da interdisciplinaridade no ensino médio politécnico: a contribuição dos saberes docentes na realidade de duas escolas do norte gaúcho. Investigações em Ensino de Ciências, Porto Alegre, v. 20, n. 2, p. 103-125, 2015.

CZERNIAK, C. M.; JOHNSON, C. C. Interdisciplinary science teaching. In: LEDERMAN, N. G.; ABELL, S. K. (Eds.). Handbook of research on science education. New York: Routledge, 2014. v. II. p. 395-411.

FAZENDA, I. C. A. Interdisciplinaridade: história, teoria e pesquisa. Campinas: Papirus, 1994.

FAZENDA, I. C. A. Interdisciplinaridade: história, teoria e pesquisa. 10 ed. Campinas: Papirus, 2002.

FEISTEL, R. A. B.; MAESTRELLI, S. R. P. Interdisciplinaridade na formação inicial de professores: um olhar sobre as pesquisas em educação em ciências. ALEXANDRIA Revista de Educação em Ciência e Tecnologia, v. 5, n. 1, p.155176, 2012.

FLICK, U. Introdução à pesquisa qualitativa. Trad. J. E. Costa. 3. ed. Porto Alegre: Artmed, 2009.

GRAY, D. E. Pesquisa no mundo real. Trad. R. C. Costa. Rev. Téc. D. Silva. 2. ed. Porto Alegre: Penso, 2012.

JAPIASSU, H. Interdisciplinaridade e patologia do saber. Rio de Janeiro: Imago, 1976.

KLEIMAN, Â. B.; MORAES, S. E. Leitura e interdisciplinaridade: tecendo redes nos projetos da escola. Campinas: Mercado das Letras, 1999.

LAVAQUI, V.; BATISTA, I. L. Interdisciplinaridade em ensino de ciências e de matemática no Ensino Médio. Ciência \& Educação, Bauru, v. 13, n. 3, p. 399420, 2007.

LEFÈVRE, F.; LEFÈVRE, A. M. C. Depoimentos e discursos: uma proposta de análise em pesquisa social. Brasília: Liber Livro, 2005a.

LEFÈVRE, F.; LEFĖVRE, A. M. C. O discurso do sujeito coletivo: um novo enfoque em pesquisa qualitativa (desdobramentos). Caxias do Sul: EDUCS, 2005b. 
LENOIR, Y. Didática e interdisciplinaridade: uma complementaridade necessária e incontornável. In: FAZENDA, I. C. A. (Org.). Didática e interdisciplinaridade. Campinas: Papirus, 2001. p. 45-75.

MACKEDANZ, L. F.; ROSA, L. S. O discurso da interdisciplinaridade e as impressões docentes sobre 0 ensino de Ciências Naturais no Ensino Fundamental. Revista Thema, Pelotas, v. 13, n. 3, p. 140-152, 2016.

MANGINI, F. N. R.; MIOTO, R. C. T. A interdisciplinaridade na sua interface com o mundo do trabalho. Revista Katálysis, Florianópolis, v. 12, n. 2, p. 207-215, 2009.

MARTINS, M.; LECHUGO, C. P.; GOERGEN, P. Transdisciplinaridade: discurso ou realidade? In: CONGRESO LATINOAMERICANO DE FILOSOFÍA DE LA EDUCACIÓN, 2., 2013, Montevideo. Anais... Montevideo: Universidad de la República, 2013, p. 36-47.

MOZENA, E. R.; OSTERMANN, R. Uma revisão bibliográfica sobre a interdisciplinaridade no ensino das ciências da natureza. Revista Ensaio, Belo Horizonte, v. 16, n. 2, p. 185-206, 2014.

PIERSON, A. H. C.; NEVES, M. R. Interdisciplinaridade na formação de professores de ciências: conhecendo obstáculos. Revista Brasileira de Pesquisa em Educação em Ciências, Belo Horizonte, v. 1, n. 2, p. 120-131, 2001.

$\mathrm{POMBO}, \mathrm{O}$. Interdisciplinaridade e integração dos saberes. Liinc em Revista, Rio de Janeiro, v. 1, n. 1, p. 3-15, 2005.

REZENDE, F.; QUEIROZ, G. R. P. C. Apropriação discursiva do tema interdisciplinaridade por professores e licenciandos em fórum eletrônico. Ciência \& Educação, Bauru, v. 15, n. 3, p. 459-478, 2009.

RIBEIRO, J. S. Interdisciplinaridade. Informática na Educação: Teoria \& Prática, Porto Alegre, v. 8, n. 2, p. 21-34, 2005.

SCHMITT, V.; TRAVASSOS, L. P.; FIALHO, F. A. P.; REMOR, C. A. M. Interdisciplinaridade e pós-graduação. Revista de Biologia e Ciências da Terra, São Cristóvão, v. 6, n. 2, p. 295-304, 2006.

THIESEN, J. S. A interdisciplinaridade como um movimento articulador no processo ensino-aprendizagem. Revista Brasileira de Educação, Rio de Janeiro, v. 13, n. 39, p. 545-598, 2008.

Recebido em: Janeiro de 2017 Aceito em: Março de 2017 